\title{
Dual roles of IL-18 in colitis through regulation of the function and quantity of goblet cells
}

\author{
ZHICHEN PU ${ }^{1,2^{*}}$, YUAN CHE $^{1 *}$, WEIWEI ZHANG ${ }^{3 *}$, HUI SUN $^{1}$, TUO MENG $^{1}$, \\ HAITANG XIE ${ }^{2}$, LIJUAN CAO ${ }^{1}$ and HAIPING HAO ${ }^{1}$
}

\begin{abstract}
${ }^{1}$ State Key Laboratory of Natural Medicines, Key Laboratory of Drug Metabolism and Pharmacokinetics, China Pharmaceutical University, Nanjing, Jiangsu 210009; ${ }^{2}$ Department of Clinical Pharmacy, Yijishan Hospital of Wannan Medical College, Anhui Provincial Center for Drug Clinical Evaluation, Wuhu, Anhui 241001;

${ }^{3}$ Department of Pharmacy, Fourth People's Hospital of Maanshan, Maanshan, Anhui 243031, P.R. China
\end{abstract}

Received October 31, 2018; Accepted March 13, 2019

DOI: $10.3892 / \mathrm{ijmm} .2019 .4156$

\begin{abstract}
The main aim of the present study was to investigate the dual roles and mechanism of interleukin (IL)-18 in dextran sulfate sodium (DSS)-induced colitis. Firstly, meta-analysis was used to explore whether the levels of IL-18 were different in patients with colon cancer or inflammatory bowel disease. The results demonstrated that IL-18 (rs187238, -137G/C) increased the incidence rate of colon cancer in patients, while IL-18 (rs187238, -137G/C) decreased the incidence rate of ulcerative colitis or Crohn's disease in patients. Therefore, IL-18 (rs187238, -137G/C) may have a dual function in colitis. Next, the functional role of IL-18 in colitis was further investigated, by use of a DSS-induced colitis mouse model. Pre-treatment of the mice with IL-18 increased body weight, augmented colon length, reduced inflammatory infiltration, promoted mucin (Muc)-2 expression, increased the function and quantity of goblet cells and increased the mRNA levels of resistin-like molecule (RELM) $\beta$ and trefoil factor family (TFF) 3 in mice with DSS-induced colitis, through the IL-22/STAT3 pathway. By contrast, treatment with IL-18 at later stages of the disease reduced body weight, decreased colon length, enhanced inflammatory infiltration and reduced Muc-2 expression, decreased the function and quantity of goblet cells and inhibited the mRNA levels of RELM $\beta$ and TFF3 in mice with DSS-induced colitis. In conclusion, IL-18 served a dual function in colitis by regulating the function
\end{abstract}

Correspondence to: Professor Lijuan Cao or Professor Haiping Hao, State Key Laboratory of Natural Medicines, Key Laboratory of Drug Metabolism and Pharmacokinetics, China Pharmaceutical University, 24 Tongjiaxiang Street, Nanjing, Jiangsu 210009, P.R. China

E-mail: caolijuan0702@cpu.edu.cn

E-mail: hhp_770505@hotmail.com

${ }^{*}$ Contributed equally

Key words: interleukin-18, colitis, goblet cell, interleukin-22, signal transducer and activator of transcription 3 of goblet cells. The anti-inflammatory effects of IL-18 were observed in the early stage of colitis-induced inflammation, while the pro-inflammatory effects were observed in the later stages of the disease.

\section{Introduction}

The gastrointestinal tract is constantly exposed to various symbiotic bacteria and potential harmful microorganisms. Therefore, it is necessary to control the balance of the local immune system (1). Pathogenic immune response occurs upon disturbance of the enteric bacterial homeostasis, which is generally called inflammatory bowel disease (IBD). This syndrome includes two types of intestinal diseases, ulcerative colitis (UC) and Crohn's disease (CD) (2). These two diseases are major health problems in western society, with an incidence of $\sim 200 / 100,000$. In UC, the inflammation is restricted in the colonic mucous layer, while $\mathrm{CD}$ can affect the entire intestinal tract (3). IBD mainly attacks at the early adulthood, accompanied with abdominal pain, weight loss, diarrhea and proctorrhagia. The risk factors of IBD development include genetic and environmental factors (4). On the one hand, a study with twins and immediate relatives with high IBD morbidity has demonstrated the contribution of genetics to disease susceptibility (4). Multiple IBD-related genes have been identified in recent years. However, environmental conditions, including high fat diet, sugar diet, smoking, stress and frequent use of antibiotics, are also significantly associated with higher risk of IBD. Such findings demonstrate the influence of environmental factors on IBD (5).

Interleukin (IL)-18 levels are elevated in patients with active inflammatory disease. However, a mouse study has also demonstrated a protective role for IL-18, since I1-18 ${ }^{-/}$and Il-18 receptor 1 (Il-18R1) $)^{-/}$mice were more susceptible to colitis and colitis-related colon tumors (6). Such discrepancy may reflect the different roles of IL-18 depending on timing and background. During the dextran sulfate sodium (DSS)-induced inflammatory process, early production of IL-18 is vital for epithelial restoration and inflammation recession. However, in the presence of chronic and dysfunctional inflammation, excessive IL-18 may aggravate disease progression (7). 
IL-22 is a member of the IL-10 cytokine family, and it is strongly expressed in CD and UC. IL-22 can bind with the dimer membrane receptor IL-22R that is only expressed in epithelial cells, rendering IL-22 an important mediator between the immune system and the epithelial system (8). A mouse model has suggested that IL-22 serves a key role in restoring enteric dynamic balance during acute inflammatory colitis (9). The protection of IL-22 is firstly achieved through inducing the expression of anti-microbial peptides (AMPs) in epithelial cells (9). In addition, it can intensify the epithelial barrier function through mucus production by goblet cells and restoration of epithelial tight junctions (10). Secondly, the IL-22-induced survival and proliferation of epithelial cells can promote epithelial wound healing (11). However, the deterioration or uncontrollable effect of IL-22 can result in other pathological conditions, such as psoriasis and colorectal cancer. IL-22 is suggested to be soluble, and IL-22 binding protein (IL-22BP) is a specific and effective inhibitor. Consequently, another hypothesis for the increased incidence of experimental colon tumors in $1122 \mathrm{bp}^{-/-}$mice lies in the suppression of IL-22-induced epithelial cell proliferation (12). Additionally, expression of IL-22 and IL-22BP is regulated in the intestinal tissues during injury (12).

The present study investigated the dual roles and the mechanisms of IL-18 in a mouse model of DSS-induced colitis.

\section{Materials and methods}

Experimental model. Animal experiments were approved by the Institutional Animal Care and Welfare Committee of China Pharmaceutical University and performed in accordance with institutional protocols. Six-week-old male C57BL/6 mice (20-21 g) were obtained from the Laboratory Animal Center of Yangzhou University (Yangzhou, China), housed under standard conditions at $22 \pm 2^{\circ} \mathrm{C}, 50 \pm 10 \%$ humidity, and $12 \mathrm{~h}$ light/dark cycle and fed with standard diets and tap water ad libitum.

The mice $(n=27)$ were randomly assigned into 4 groups, in order to generate the acute colitis model: Control $(n=6)$, DSS model $(n=7)$, treatment with IL-18 $(n=7)$, pre-treatment with IL-18 $(n=7)$. Mice in the control group were given distilled water for 7 days. In the DSS model group, mice were administered normal water for 5 days, induced by oral intake of $2 \%$ DSS (w/v, dissolved in drinking water) for 7 days and then given normal water for an additional 3 days. In the IL-18 treatment group, mice were on normal water for 5 days, induced by oral intake of $2 \%$ DSS (w/v, dissolved in drinking water) for 7 days and intraperitoneally injected with $1 \mu \mathrm{g}$ of IL-18 for the last 3 days of the 7 day DSS induction period; mice were also intraperitoneally injected with $1 \mu \mathrm{g}$ of IL-18 for 1 day at the 3 day normal water recovery period. Finally, in the IL-18 pre-treatment group, mice were intraperitoneally injected with $1 \mu \mathrm{g}$ of IL-18 for 3 days during the initial normal water 5 day period, then intraperitoneally injected again with $1 \mu \mathrm{g}$ of IL-18 for 3 days at the beginning of the DSS induction for 7 days, followed by recovery on normal water for 3 days (Fig. 1).

Reverse transcription-quantitative polymerase chain reaction ( $R T-q P C R)$. TRIzol reagent (Invitrogen; Thermo Fisher Scientific, Inc., Waltham, MA, USA) was used to extract total RNA from cells, according to manufacturer's instructions. cDNA was synthesized using SuperScript VILO cDNA Synthesis kit (cat. no. 11754250, Invitrogen; Thermo Fisher Scientific, Inc.). qPCR was performed with SYBR-Green Master Mix (ABI; Thermo Fisher Scientific, Inc.) on an ABI PRISM 7000 Sequence Detection (Applied Biosystems; Thermo Fisher Scientific, Inc.) under the following conditions: $50^{\circ} \mathrm{C}$ for $5 \mathrm{~min}, 95^{\circ} \mathrm{C}$ for $10 \mathrm{~min}$, followed by 40 cycles at $95^{\circ} \mathrm{C}$ for $30 \mathrm{sec}$ and $60^{\circ} \mathrm{C}$ for $30 \mathrm{sec}$. Relative gene expression was analyzed using the $2^{-\Delta \Delta \mathrm{Cq}}$ method (13). The primers were as follows: Resistin-like molecule (RELM) $\beta$, forward 5'-GCTCTTCCCTTTCCTTCTCCAA-3' and reverse 5'-AAC ACAGTGTAGGCTTCATGCTGTA-3'; trefoil factor family (TFF) 3, forward 5'-CCAAGGACAGGGTGGACTG-3' and reverse 5'-AAGGTGCATTCTGCTTCCTG-3'; GAPDH, forward 5'-GGGGAAGGTGAAGGTCGGAG-3' and reverse 5'-CCTGGAGATGGTGATGGGA-3'.

Histopathological, periodic acid-Schiff (PAS) and Alcian Blue examination. Colon tissue samples were acquired and fixed with $4 \%$ paraformaldehyde for $24 \mathrm{~h}$. Colon tissues were then dehydrated, embedded in paraffin, and sliced to $5 \mu \mathrm{m}$ thickness sections. Sections were stained with hematoxylin and eosin (H\&E), PAS and Alcian Blue for $5 \mathrm{~min}$. Colon tissue samples were observed using an inverted fluorescence microscope (Zeiss Axio Observer A1; Carl Zeiss AG, Oberkochen, Germany).

\section{Meta-analysis}

Literature search. A comprehensive literature search was conducted in the platforms of PubMed, Embase, Cochrane Library, and Web of Science. The last search was performed on June 2018. Words adopted were as follows: 'IL-18', 'IL-18 gene polymorphism', 'intestinal disease', 'ulcerative colitis', 'colon cancer', 'Crohn's disease' and 'inflammatory bowel disease'. The reference lists of the full-text articles were manually examined to identify any additional publications relevant to our analysis.

Study selection. The following inclusion criteria were used to select eligible studies: i) The diagnosis of Crohn's disease or colon cancer was pathologically confirmed; ii) the prognostic value of bile acid levels in people with colon cancer, ulcerative colitis or Crohn's disease were reported; iii) the levels of bile acid were tested by gaschromatograph, thin-layer chromatography or gas-liquid chromatography; iv) hazard ratios (HRs) and their 95\% confidence intervals (CIs) for bile acid levels analysis were reported in text or could be computed from given data. The exclusion criteria were: i) Abstract, review, case report or comment letter; ii) animal studies; iii) duplicate publications.

ELISA kits. Colon tissue samples were acquired and lyzed using RIPA assay (Beyotime Institute of Biotechnology, Haimen, China). Protein was quantified using a BCA kit (Beyotime Institute of Biotechnology). A total of $10 \mu \mathrm{g}$ protein was used per sample to measure the levels of IL-22 (cat. no EH027-96; ExCell Bio, Shanghai, China) and IL-22BP (cat. no. EK2506; Nanjing Senberga Biotechnology Co., Ltd., Nanjing, China) using ELISA kits. 

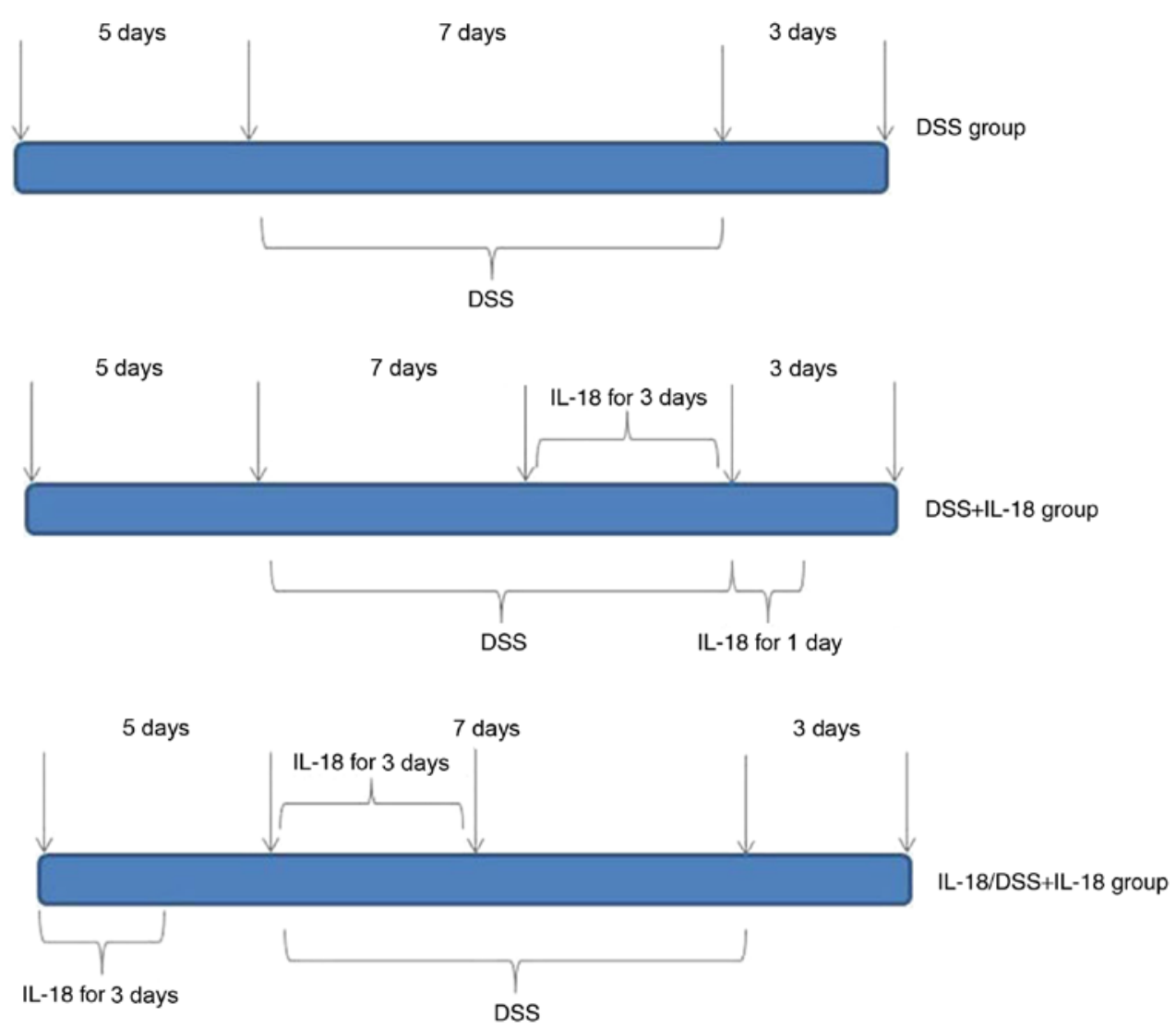

Figure 1. Timing of administrations in the experimental mouse groups. DSS, dextran sulfate sodium; IL, interleukin.

$I L-18$ recombinant protein. $\mathrm{PCR}$ was used to generate an IL-18-expressing plasmid. The coding sequence (CDS) of IL-18 was 479 bp and the size of the pET28a vector plasmid was 5,369 bp. A His tag (CATCATCACCATCACCAT) was added into the CDS of IL-18, using the primers 5'-GCTCTA GACATCATCACCATCACCATAAAGATGG-3' and 5'-CCC AAGCTTTTGCTTCTGATC-3' for the amplification. The thermocycling conditions were: $94^{\circ} \mathrm{C}$ for $5 \mathrm{~min}$, followed by 40 cycles of $94^{\circ} \mathrm{C}$ for $30 \mathrm{sec}, 58^{\circ} \mathrm{C}$ for $30 \mathrm{sec}$ and $65^{\circ} \mathrm{C}$ for $30 \mathrm{sec}$. The IL-18-expressing plasmid was then transformed into BL21 bacterial cells, and clones were selected with kanamycin. For protein expression, BL21 bacteria were grown in LB medium containing $1 \mathrm{mM} \mathrm{IPTG}$ at $30^{\circ} \mathrm{C}$ for $12 \mathrm{~h}$. The His tag protein purification kit (cat. no. P2226; Beyotime Institute of Biotechnology) was used to extract and purify the IL-18 recombinant protein.

Immunofluorescence. Colon tissue samples were acquired and fixed with $4 \%$ paraformaldehyde for $24 \mathrm{~h}$. Colon tissues were then dehydrated, embedded in paraffin, sliced to $5 \mu \mathrm{m}$ thickness sections. Sections were permeabilized by $0.25 \%$ Triton X-100 for $10 \mathrm{~min}$ at room temperature and blocked with $5 \%$ bovine serum albumin in PBS for $1 \mathrm{~h}$ at room temperature. Sections were incubated with mucin (Muc)-2 targeting antibody (cat. no. sc-59859; 1:100; Santa Cruz Biotechnology, Inc., Dallas, TX, USA) at $4^{\circ} \mathrm{C}$ overnight and washed with PBST for $15 \mathrm{~min}$ at room temperature. Sections were incubated with secondary peroxidase-conjugated goat anti-rabbit IgG (cat. no. sc-362272, 1:100; Santa Cruz Biotechnology, Inc.) antibody for $2 \mathrm{~h}$ at room temperature. Sections were then counterstained with DAPI for $15 \mathrm{~min}$. Colon tissue samples were observed using an inverted fluorescence microscope (Zeiss Axio Observer A1; Carl Zeiss AG).

Western blot analysis. Colon tissue samples were acquired and lyzed with RIPA buffer (Beyotime Institute of Biotechnology). Protein was quantified using a BCA kit (Beyotime Institute of Biotechnology). A total of $100 \mu \mathrm{g}$ protein per sample was boiled for 5 min prior to separation by $10 \%$ SDS-PAGE, and then transferred onto nitrocellulose membranes (Pall Life Sciences, Port Washington, NY, USA). Membranes were blocked with $5 \%$ non-fat milk at $37^{\circ} \mathrm{C}$ for $1 \mathrm{~h}$ and incubated with corresponding primary antibodies: IL-18 (cat. no. BS6823; 1:2,000; Bioworld Technology, Inc. St. Louis Park, MN, USA), phosphorylated (p-) signal transducer and activator of transcription (Stat) 3 (cat. no. 9145; 1:1,000; Cell Signaling Technology, Inc., Danvers, MA, USA), total Stat3 (cat. no. 12640; 1:1,000; Cell Signaling Technology, Inc.) and GAPDH (cat. no. AP0063; 1:5,000; Bioworld Technology, Inc.) at $4{ }^{\circ} \mathrm{C}$ overnight. Following 3 washes for $10 \mathrm{~min}$ in TBST, the membranes were incubated with anti-mouse or anti-rabbit horseradish peroxidase-conjugated secondary antibodies (1:5,000; Santa Cruz Biotechnology, Inc.) at $37^{\circ} \mathrm{C}$ for $1 \mathrm{~h}$. Enhanced chemiluminescent reagent (Beyotime Institute of Biotechnology) was used to develop the blots and protein was analyzed using Image Lab 3.0 (Bio-Rad Laboratories, Inc., Hercules, CA, USA).

Statistical analysis. Odds ratio (OR) and 95\% confidence intervals (CI) were applied to continuous outcomes: The fixed-effects model was used to calculate continuous outcomes. Statistical heterogeneity was assessed using the I2 statistic, where a 
Table I. Basic characteristics of included studies.

\begin{tabular}{|c|c|c|c|c|c|c|}
\hline Study & Year & Country & Ethnicity & Cases & Group cases & Mutation site \\
\hline Nikiteas et al & 2007 & Greece & Europe & 173 & $89 / 84$ & 607 \\
\hline Haghshenas et al & 2009 & Iran & Europe & 455 & $143 / 312$ & 607,137 \\
\hline Guo et al & 2012 & China & Asia & 330 & $170 / 160$ & 607,137 \\
\hline Ben et al & 2011 & Tunisia & Africa & 246 & $105 / 59 / 100$ & 607,137 \\
\hline Takagawa et al & 2005 & Japan & Asia & 627 & $210 / 205 / 212$ & 607,137 \\
\hline Glas et al & 2005 & Germany & Europe & 615 & $210 / 140 / 254$ & 607,137 \\
\hline Aizawa et al & 2005 & Japan & Asia & 560 & $158 / 198 / 204$ & 607,137 \\
\hline Haas et al & 2005 & Germany & Europe & 1052 & $470 / 235 / 347$ & 137 \\
\hline Bank et al & 2015 & Denmark & Europe & 1830 & $624 / 411 / 795$ & 607,137 \\
\hline
\end{tabular}

Mutation site 607, rs1946518; mutation site 137, rs187238.

Table II. Pooled HRs and 95\% CIs in meta-analysis of patients with colon cancer.

\begin{tabular}{|c|c|c|c|c|c|c|}
\hline \multirow[b]{2}{*}{ Variable } & \multirow[b]{2}{*}{ Studies } & \multicolumn{2}{|c|}{ Heterogeneity } & \multirow[b]{2}{*}{ HR } & \multirow[b]{2}{*}{$95 \% \mathrm{CI}$} & \multirow[b]{2}{*}{ P-value } \\
\hline & & $\mathrm{I} 2(\%)$ & P-value & & & \\
\hline $137 \mathrm{GC}+\mathrm{CC}$ & 2 & 87 & 0.006 & 1.26 & $0.94-1.69$ & 0.13 \\
\hline $137 \mathrm{GC}$ & 2 & 46 & 0.17 & 1.41 & $1.03-1.91$ & 0.03 \\
\hline $137 \mathrm{CC}$ & 2 & 87 & 0.006 & 0.72 & $0.40-1.30$ & 0.27 \\
\hline
\end{tabular}

HR, hazard ratio; CI, confidence interval.

value of $50 \%$ or greater indicated heterogeneity. Publication bias was evaluated using funnel plots. Statistical analyses for the meta-analysis were performed with Revman (version 5.3). Experimental data were expressed as the mean \pm standard deviation, and analyzed using SPSS 17.0 (SPSS, Inc., Chicago, IL, USA). Differences between groups were compared with one-way analysis of variance and Tukey's post hoc test. $\mathrm{P}<0.05$ was considered to indicate a statistically significant difference.

\section{Results}

Mutation rate of $I L-18$ (rs187238, -137G/C) in patients with colon cancer. Firstly, a meta-analysis was performed to explore whether the levels of IL-18 were different in patients with colon cancer. A total of 11 (14-23) full-text articles were evaluated for eligibility (Table I), which were published from 2005 to 2015, with 5,888 patients enrolled. As illustrated in Fig. 2A and C and Table II, the incidence rate of colon cancer in patients was not affected by IL-18 (rs187238, -137GC+CC or CC), compared with IL-18 -137G/G group. However, IL-18 (rs187238, -137GC) increased the incidence rate of colon cancer in patients compared with IL-18 $-137 \mathrm{G} / \mathrm{G}$ (Fig. 2B; Table II). Therefore, these results demonstrated that IL-18 (rs187238, -137G/C) increased the incidence rate of colon cancer in patients.

Mutation rate of $I L-18$ (rs187238, $-137 G / C)$ in patients with Crohn's disease or ulcerative colitis. The incidence rate of Crohn's disease in patients was found to not be influenced by IL-18 (rs187238, $-137 \mathrm{GC}+\mathrm{CC}$ or GC) compared with the IL-18 -137GG group (Fig. 3A and B; Table III). However, IL-18 (rs187238, -137CC) reduced the incidence rate of Crohn's disease in patients, compared with the IL-18 -137GG group (Fig. 3C; Table III). In European continental ancestry patients, IL-18 (rs187238, $-137 \mathrm{GC}+\mathrm{CC}$ or CC) reduced the incidence rate of Crohn's disease in patients, compared with the IL-18 -137GG group (Fig. 4A and C; Table III). In addition, the incidence rate of Crohn's disease in patients was not affected by IL-18 (rs187238, -137GC), compared with the IL-18 -137GG group (Fig. 4B; Table III). In European continental ancestry patients, IL-18 (rs187238, -137GC+CC) reduced the incidence rate of ulcerative colitis in patients, compared with the IL-18 -137GG group (Fig. 5A; Table III). However, the incidence rate of ulcerative colitis in patients was not influenced by IL-18 (rs187238, -137GC or CC), compared with the IL-18 -137GG group (Fig. 5B and C; Table III). These results demonstrated that IL-18 (rs187238, -137G/C) decreased the incidence rate of ulcerative colitis or Crohn's disease in patients. However, IL-18 (rs187238, -137G/C) may have a dual role in colitis, therefore, further study was necessary to fully elucidate the mechanism of IL-18 action in colitis.

Construction and verification of IL-18 plasmid. An IL-18 expression plasmid was constructed. As illustrated in Fig. 6A and B, the coding sequence (CDS) of IL-18 was $479 \mathrm{bp}$ and the size of the pET28a vector plasmid was 5,369 bp. Gene sequencing was performed to confirm that the resulting CDS of IL-18 was correct (Fig. 6C). The IL-18-expressing 


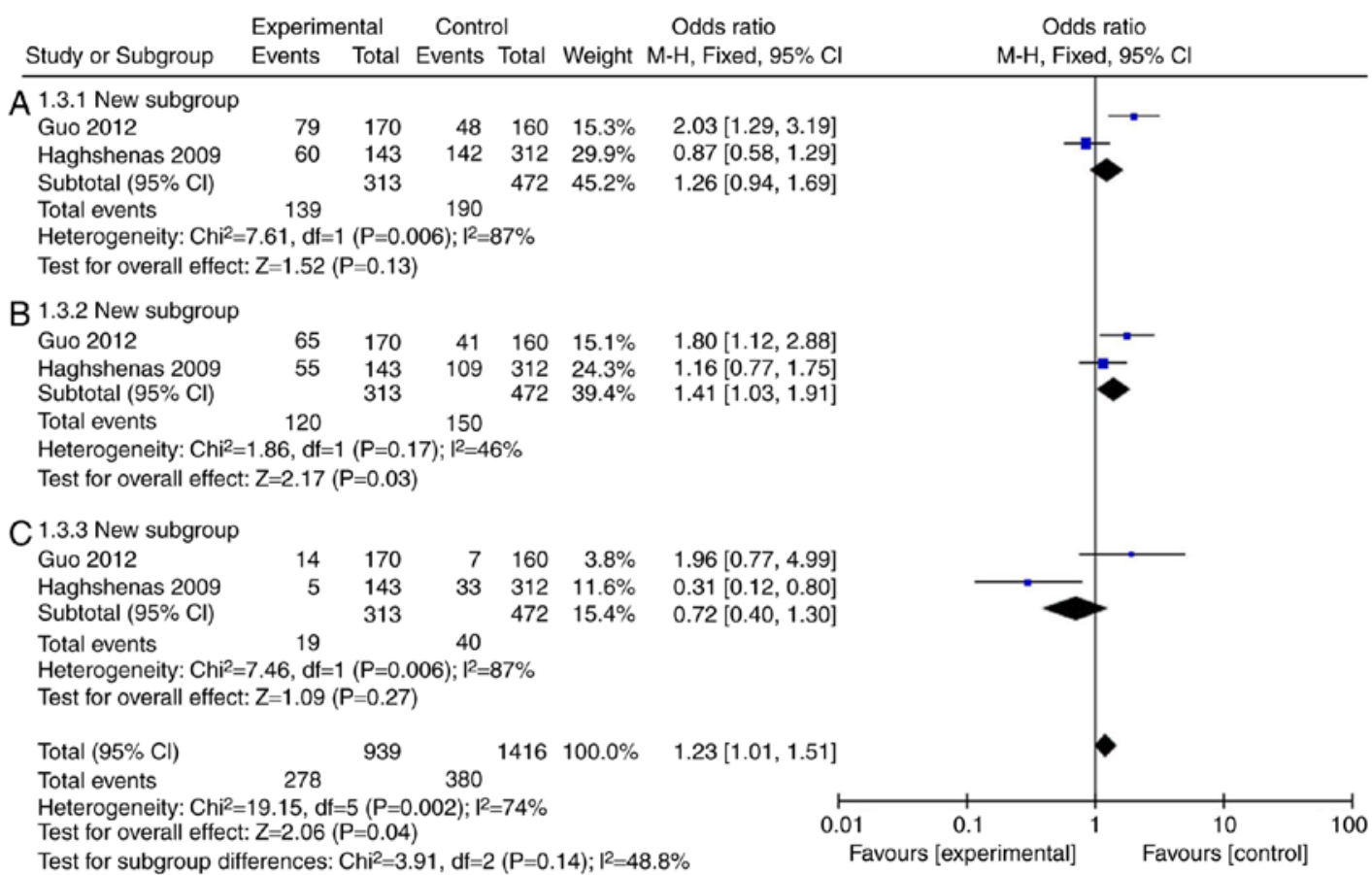

Figure 2. Mutation rate of IL-18 (rs187238, -137G/C) in patients with colon cancer. Statistical analysis of (A) IL-18 -137GC+CC vs. GG, (B) -137GC vs. GG, and (C) $-137 \mathrm{CC}$ vs. GG in patients with colon cancer. IL, interleukin; CI, confidence interval.

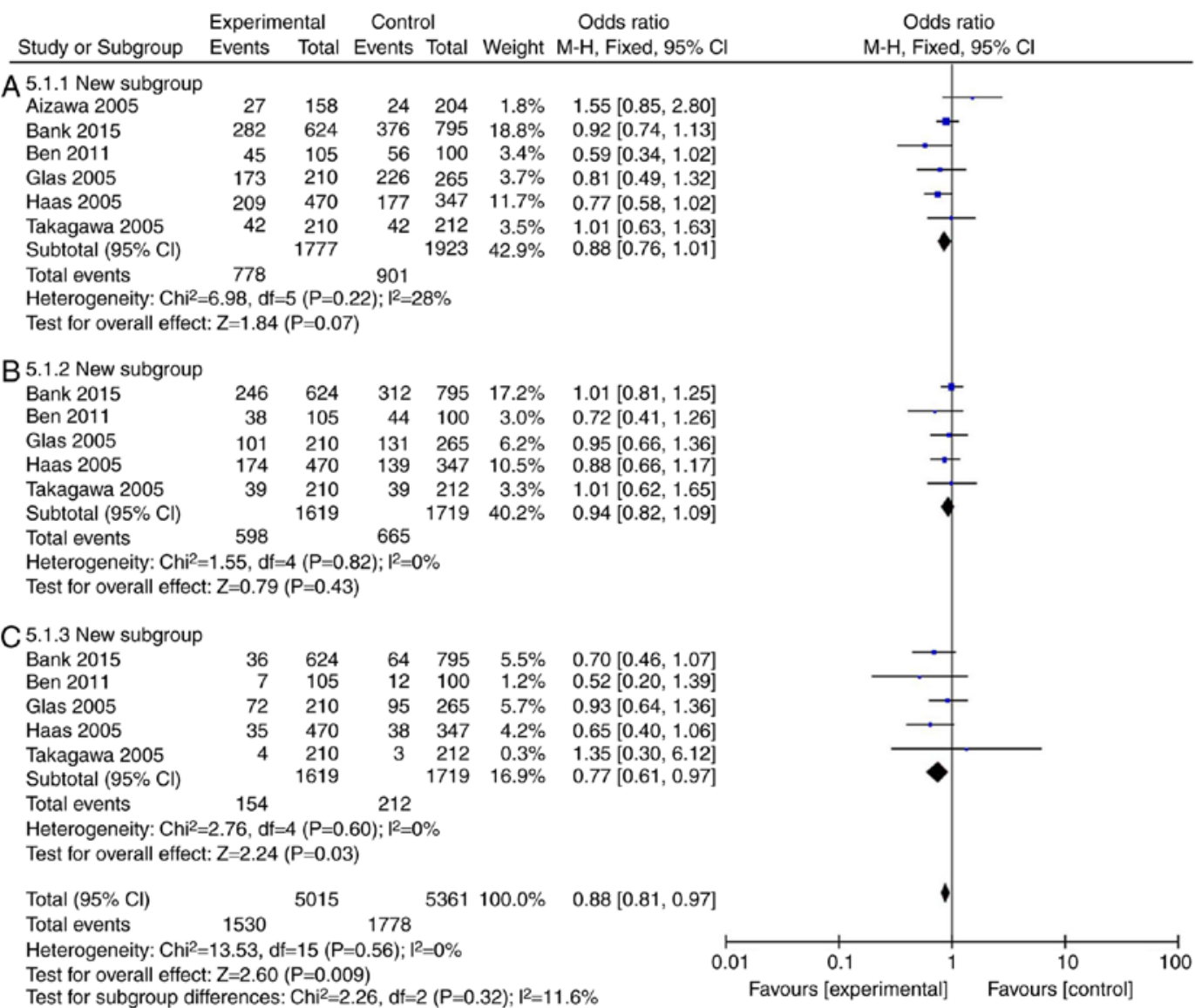

Figure 3. Mutation rate of IL-18 (rs187238, -137G/C) in patients with Crohn's disease or ulcerative colitis. Statistical analysis of (A) IL-18 -137GC+CC vs. GG, (B) -137GC vs. GG and (C) -137CC vs. GG in patients with Crohn's disease. IL, interleukin; CI, confidence interval.

plasmid was transformed into BL21 bacterial cells, and clones were selected with kanamycin (Fig. 6D). Western blot analysis was used to confirm that the generated IL-18 plasmid successfully expressed the IL-18 protein (Fig. 6E). 
Table III. Pooled HRs and 95\% CIs in meta-analysis of patients with CD and UC.

\begin{tabular}{|c|c|c|c|c|c|c|}
\hline \multirow[b]{2}{*}{ Variable } & \multirow[b]{2}{*}{ Studies } & \multicolumn{2}{|c|}{ Heterogeneity } & \multirow[b]{2}{*}{ HR } & \multirow[b]{2}{*}{$95 \% \mathrm{CI}$} & \multirow[b]{2}{*}{ P-value } \\
\hline & & $\mathrm{I} 2(\%)$ & P-value & & & \\
\hline \multicolumn{7}{|l|}{$\mathrm{CD}$} \\
\hline $137 \mathrm{GC}+\mathrm{CC}$ & 6 & 28 & 0.22 & 0.88 & $0.76-1.01$ & 0.07 \\
\hline $137 \mathrm{GC}$ & 5 & 0 & 0.82 & 0.94 & $0.82-1.09$ & 0.43 \\
\hline $137 \mathrm{CC}$ & 5 & 0 & 0.60 & 0.77 & $0.61-0.97$ & 0.03 \\
\hline \multicolumn{7}{|l|}{ ECA-CD } \\
\hline $137 \mathrm{GC}+\mathrm{CC}$ & 4 & 0 & 0.44 & 0.83 & $0.71-0.97$ & 0.02 \\
\hline $137 \mathrm{GC}$ & 4 & 0 & 0.69 & 0.94 & $0.81-1.09$ & 0.40 \\
\hline $137 \mathrm{CC}$ & 4 & 0 & 0.53 & 0.76 & $0.60-0.96$ & 0.02 \\
\hline \multicolumn{7}{|l|}{$\mathrm{UC}$} \\
\hline $137 \mathrm{GC}+\mathrm{CC}$ & 4 & 47 & 0.13 & 0.83 & $0.70-0.98$ & 0.03 \\
\hline $137 \mathrm{GC}$ & 4 & 0 & 0.68 & 0.85 & $0.72-1.01$ & 0.07 \\
\hline $137 \mathrm{CC}$ & 4 & 22 & 0.08 & 0.89 & $0.66-1.21$ & 0.46 \\
\hline
\end{tabular}

HR, hazard ratio; CI, confidence interval CD, Crohn's disease; UC, ulcerative colitis; ECA, European continental ancestry.

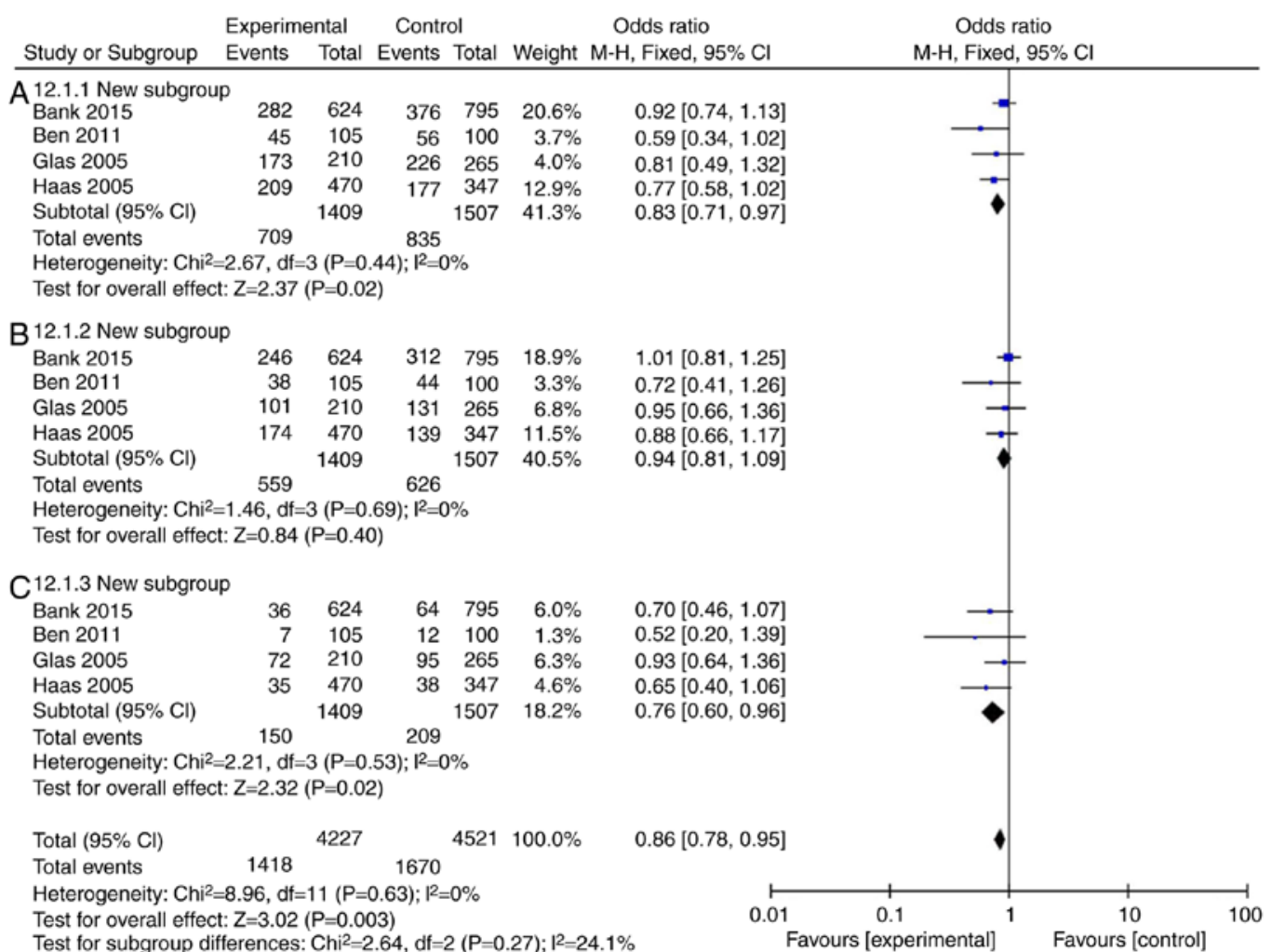

Figure 4. Mutation rate of IL-18 (rs187238, -137G/C) in European continental ancestry patients with Crohn's disease or ulcerative colitis. Statistical analysis of (A) IL-18 -137GC+CC vs. GG, (B) -137GC vs. GG, and (C) -137CC vs. GG in European continental ancestry patients with Crohn's disease. IL, interleukin; CI, confidence interval.

Dual roles of IL-18 in colitis. Next, the effects of IL-18 in colitis were investigated. Briefly, pre-treatment with IL-18 prior to DSS administration or treatment with IL-18 concomitant to DSS administration were employed in DSS-induced colitis in mice, in order to examine the effects of IL-18 at the early and late stages of the disease, respectively. As illustrated in Fig. 7, pre-treatment with IL-18 increased body weight, augmented colon length and reduced inflammatory infiltration in mice with DSS-induced colitis, compared with the DSS-induced colitis model group. By contrast, later treatment with IL-18 reduced body weight, reduced colon length and increased inflammatory infiltration in mice with DSS-induced colitis, compared with the DSS-induced colitis model group (Fig. 7). These results demonstrated that IL-18 had a dual role in colitis. In specific, 


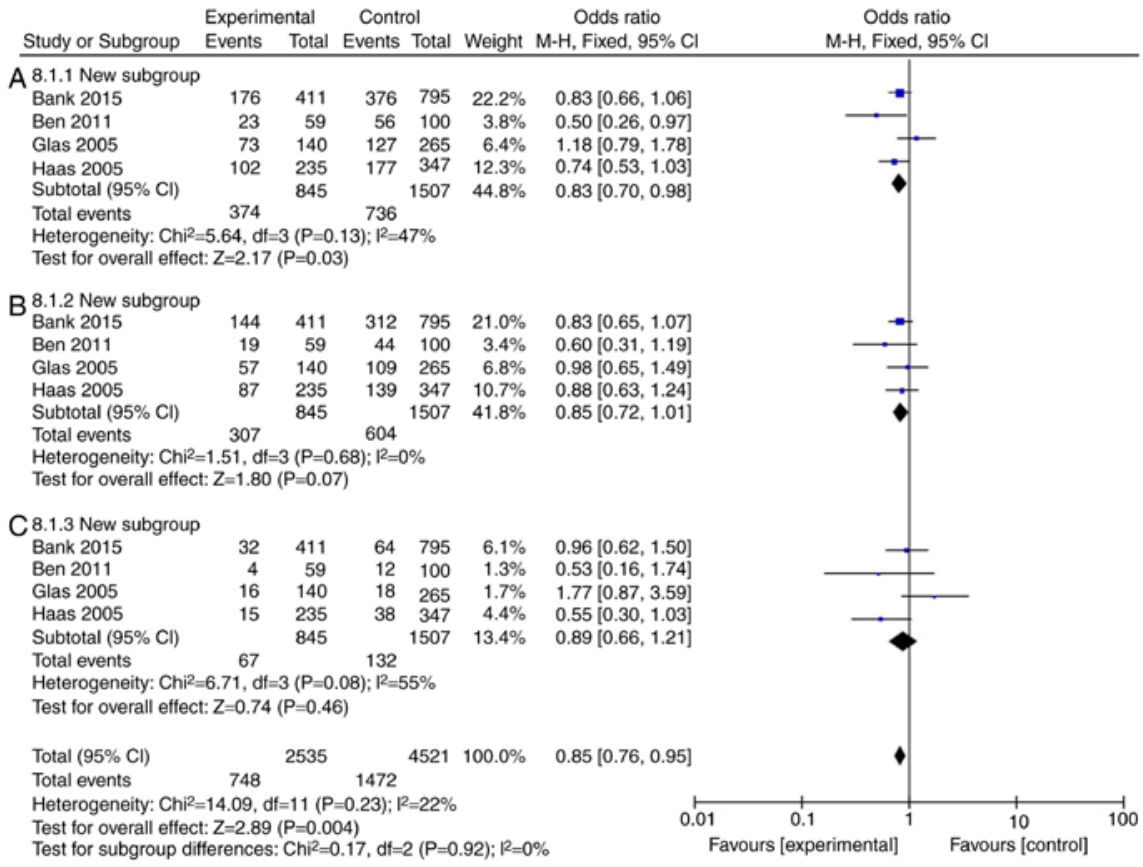

Figure 5. Mutation rate of IL-18 (rs187238,-137G/C) in European continental ancestry patients with ulcerative colitis. Statistical analysis of (A) IL-18 -137GC+CC vs. GG, (B) $-137 \mathrm{GC}$ vs. GG and (C) -137CC vs. GG in European continental ancestry patients with ulcerative colitis. IL, interleukin; CI, confidence interval.

A

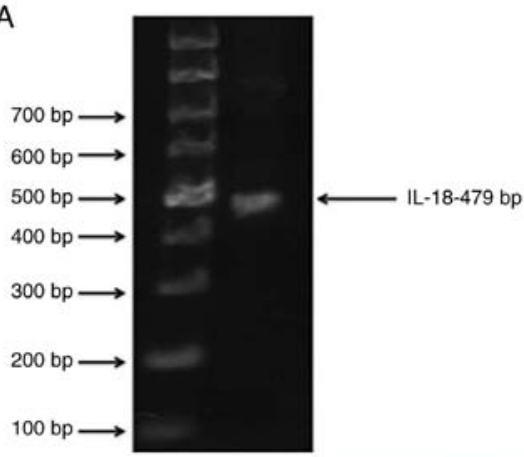

B

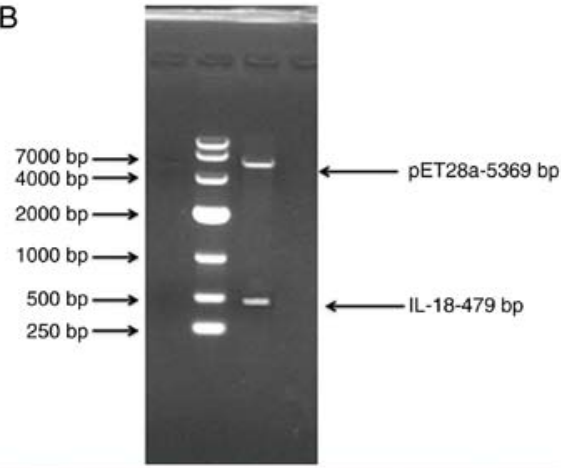

C

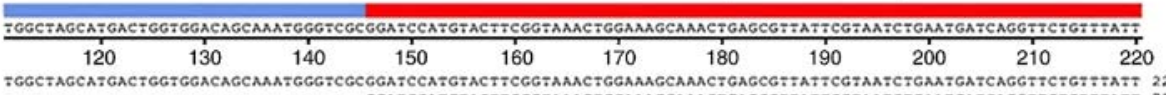

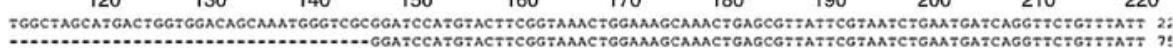

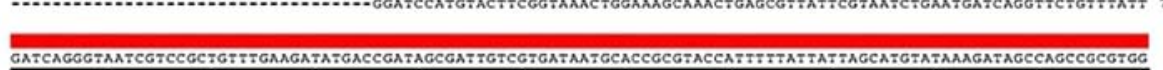

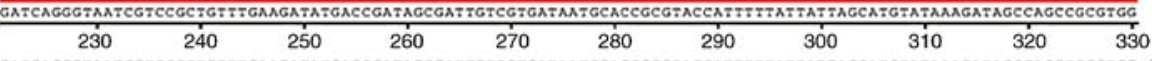

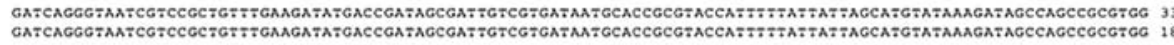

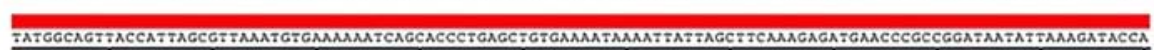

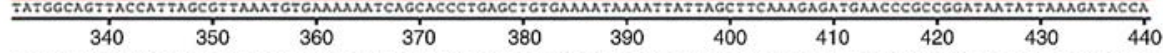

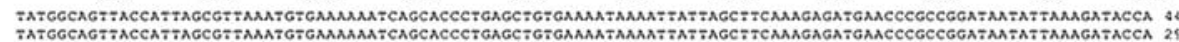

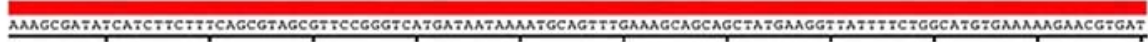
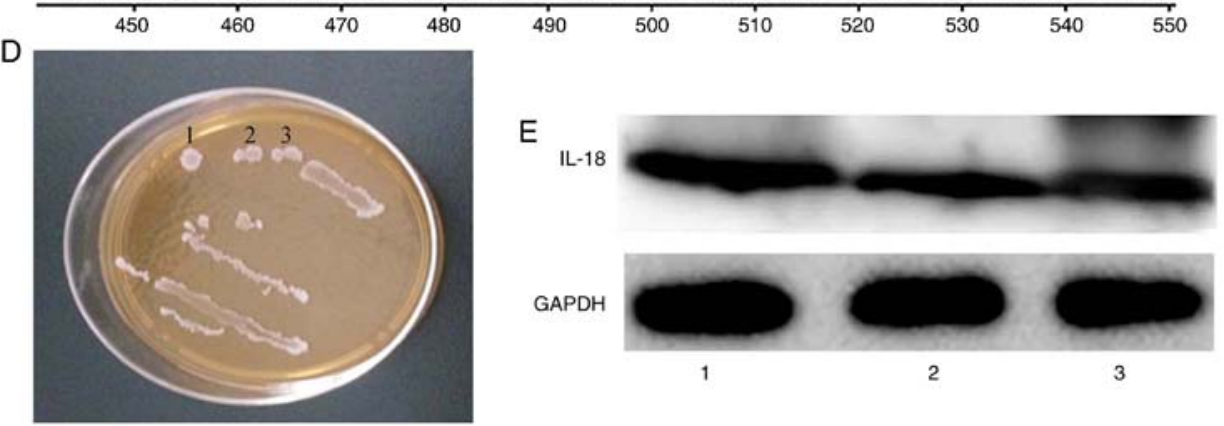

Figure 6. Construction of the IL-18 plasmid. (A) The coding sequence of IL-18 was amplified by polymerase chain reaction. The product was visualized by agarose gel electrophoresis. (B) Double digests showing the vector and the IL-18 insert. (C) Alignment of the cloned product, as verified by sequencing, to the IL-18 gene sequence. (D) BL21 bacteria expressing the IL-18 plasmid after kanamycin selection. (E) Confirmation of successful IL-18 protein expression by western blot analysis. IL, interleukin. 

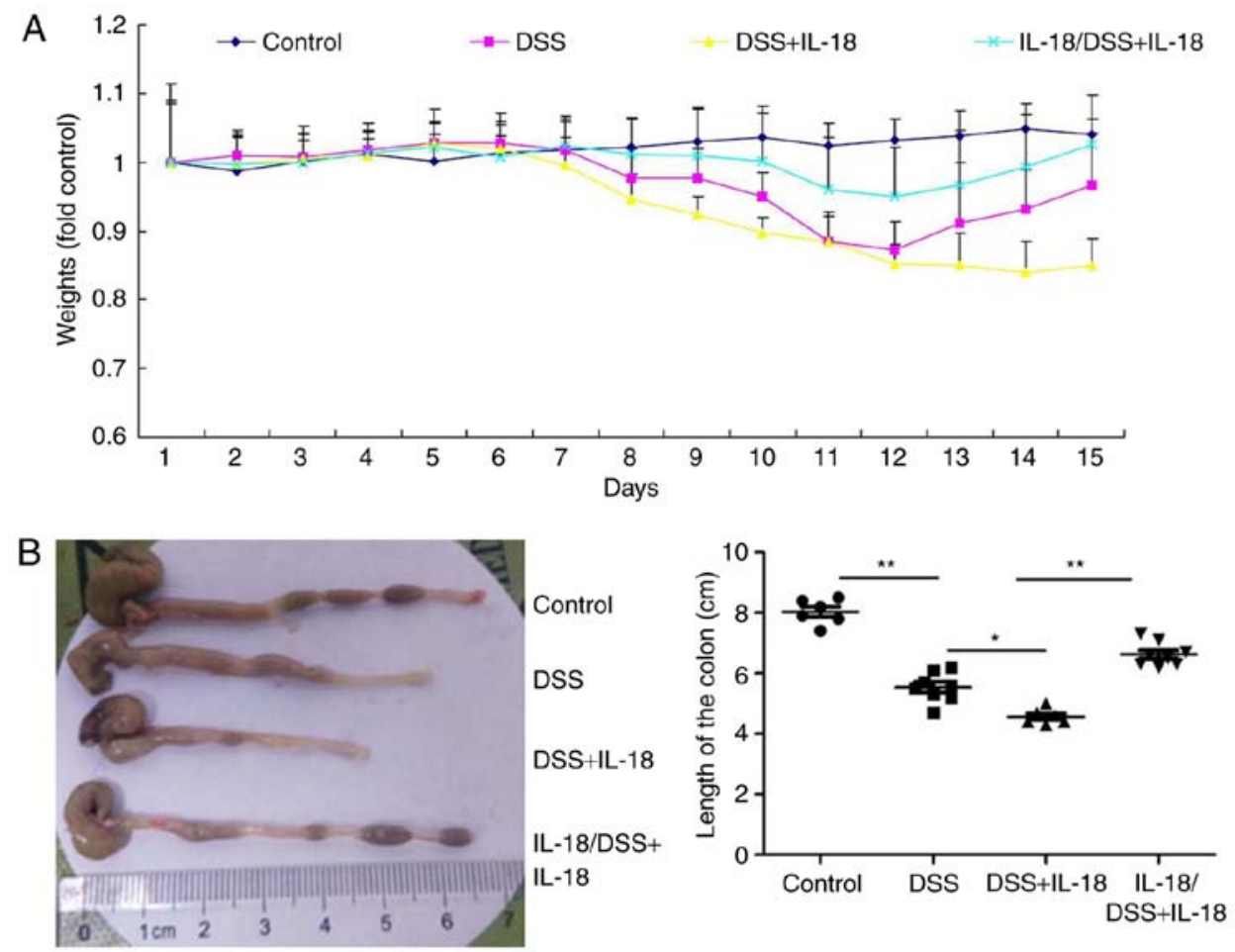

C
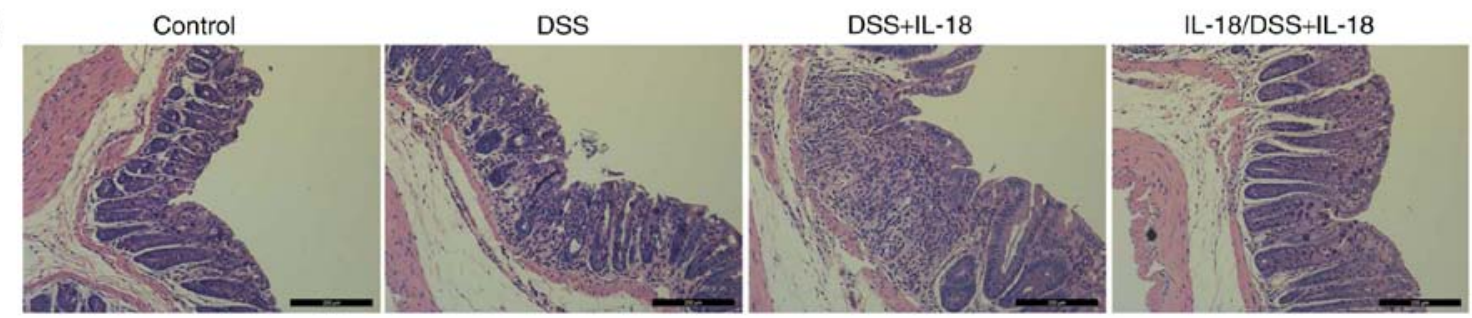

Figure 7. Dual roles of IL-18 in colitis. (A) The body weight of the experimental mice was measured throughout the experiment. (B) The length of the colon was measured per mouse group at the end of the experiment. (C) Inflammatory infiltration in colon tissues was evaluated by hematoxylin and eosin staining (magnification, $\mathrm{x} 50$ ). ${ }^{*} \mathrm{P}<0.05$ and ${ }^{* *} \mathrm{P}<0.01$ with comparisons indicated by lines. IL, interleukin; DSS, dextran sulfate sodium.

IL-18 had an anti-inflammatory effect in the early stage of the disease, but a pro-inflammatory effect in the later stage.

IL-18 regulates the function of goblet cells in colitis. Next, we explored whether the dual roles of IL-18 regulated the function of goblet cells in colitis. As illustrated in Fig. 8, Alcian Blue assay, PAS assay and Muc-2 staining revealed that pre-treatment with IL-18 promoted Muc-2 expression, increased the function and quantity of goblet cells and enhanced the mRNA levels of resistin-like molecule (RELM) $\beta$ and trefoil factor family (TFF) 3 in DSS-induced colitis, compared with the DSS-induced colitis model group. Treatment with IL-18 reduced Muc-2 expression, decreased the function and quantity of goblet cells and decreased the mRNA expression of RELM $\beta$ and TFF3 in DSS-induced colitis, compared with the DSS-induced colitis model group (Fig. 8). Therefore, the anti-inflammatory effect of IL-18 in the early stage of the disease promoted the function and quantity of goblet cells, while the pro-inflammatory effects of IL-18 hindered the function and quantity of goblet cells in the later stage.

IL-18 regulates IL-22/STAT3 signaling in colitis. The mechanism by which IL-18 may regulate the function of goblet cells in colitis was further explored. As illustrated in Fig. 9, pre-treatment with IL-18 induced the phosphorylation of Stat3, increased the levels of IL-22, but reduced the levels of the IL-22-specific inhibitor IL-22BP in DSS-induced colitis, compared with the DSS-induced colitis model group. Treatment with IL-18 at later stages suppressed the phosphorylation of Stat3, decreased the levels of IL-22 and enhanced the levels of the IL-22BP inhibitor in DSS-induced colitis, compared with the DSS-induced colitis model group (Fig. 9). Collectively, these results suggested that the anti-inflammatory effect of IL-18 in the early stage of the disease induced IL-22/STAT3 signaling, while the pro-inflammatory effects of IL-18 suppressed the IL-22/STAT3 signaling pathway in the later stage, by activating IL-22 BP.

\section{Discussion}

IBD is a major health issue, which is associated with high morbidity and mortality due to its repeated bloody diarrhea, weight loss and chronic intestinal inflammation (3). At present, the approved IBD therapy mainly depends on symptom control and inflammation suppression (24). However, the potential mechanism underlying the IBD pathogenesis 

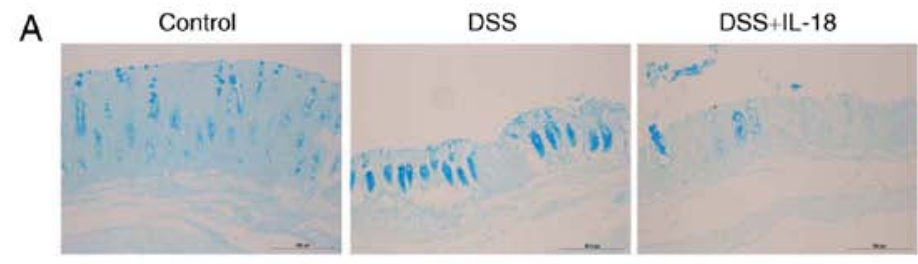

IL-18/DSS+IL-18

B

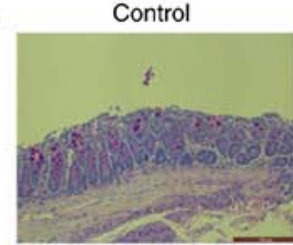

DSS

IL-18+DSS

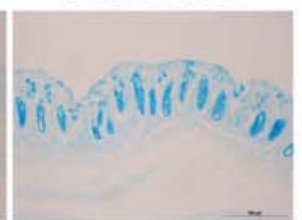

Alcian blue

C
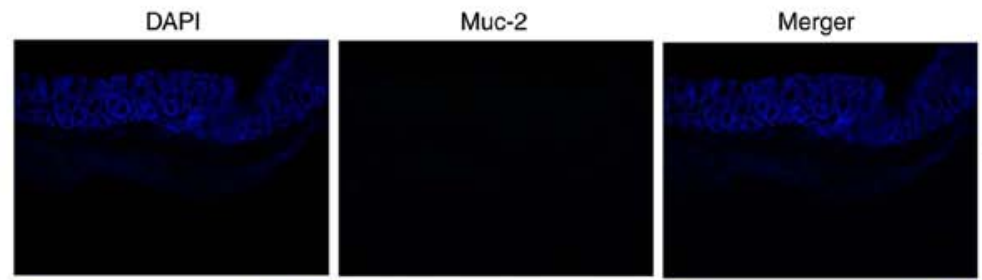

Control
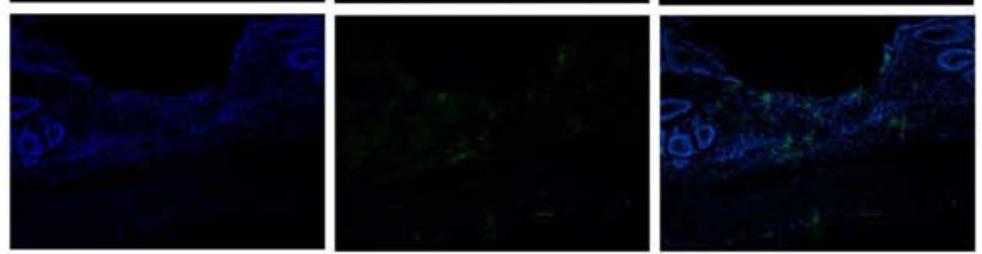

DSS
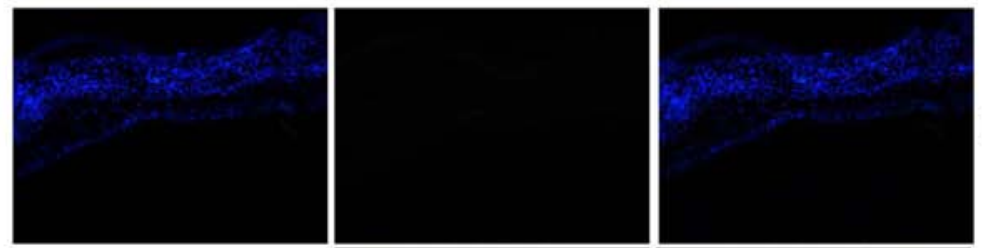

DSS+IL-18
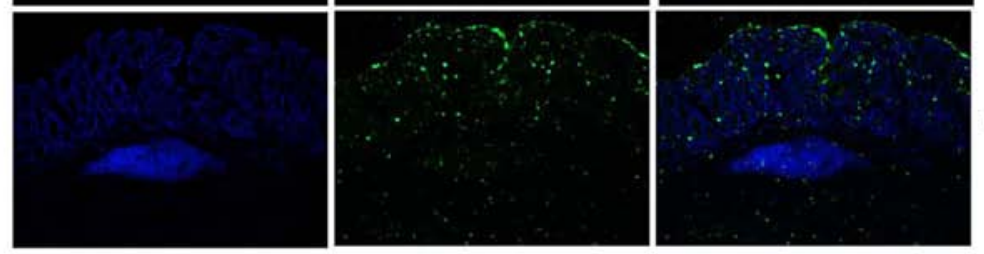

IL-18/DSS+IL-18

D

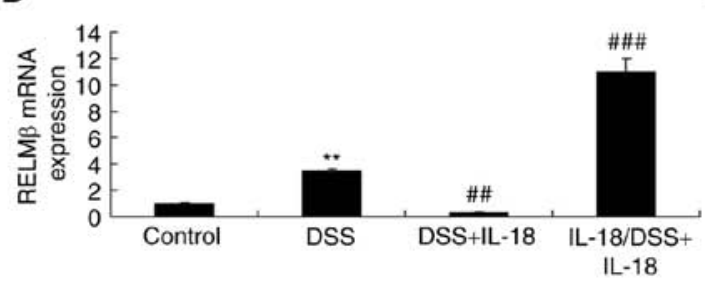

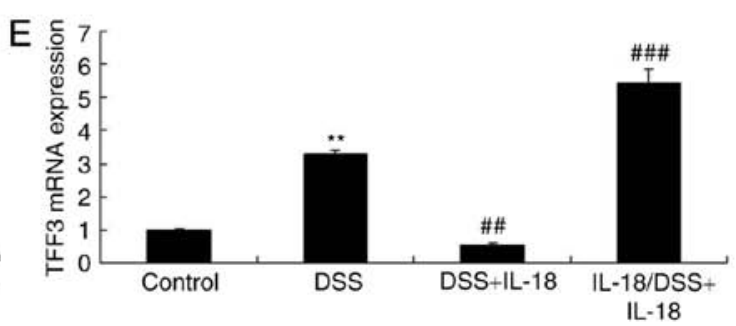

Figure 8. Dual roles of IL-18 in the function of goblet cell in colitis. (A) Alcian Blue and (B) PAS staining of colon tissues from the experimental mice. Magnification, $x 50$. (C) Immunofluorescence staining for Muc-2 in colon tissue sections from the experimental mice. Magnification, $x 50$. (D) RELM $\beta$ and

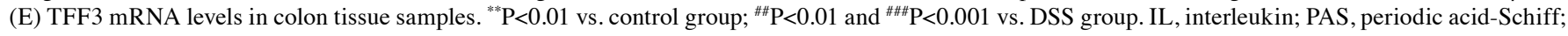
Muc-2, mucin 2; RELM $\beta$, resistin-like molecule $\beta$; TFF3, trefoil factor family 3 ; DSS, dextran sulfate sodium.

remains unclear (24). The currently popular IBD pathogenesis model is the imbalance of intestinal microbial community structure, or the abnormal immune response of symbiotic bacteria in genetically susceptible host, and/or the genesis of dysbiosis (24). Therefore, it is necessary to further elucidate the specific expression of inflammatory factors in this disease in order to determine the target treatment. In the present study, IL-18 (rs187238, -137G/C) was demonstrated to increase the incidence rate of colon cancer in patients, to decrease the incidence rate of ulcerative colitis or Crohn's disease in patients, and to have a dual function in a mouse model of colitis.

The IL-18-mediated protection mechanism remains unclear. A previous study indicates that IL-18 is mainly expressed in epithelial cells, and that the epithelium-derived IL-18 is important to prevent DSS-induced injury (25). IL-18 production is also associated with upregulation of IL-22, and 
A

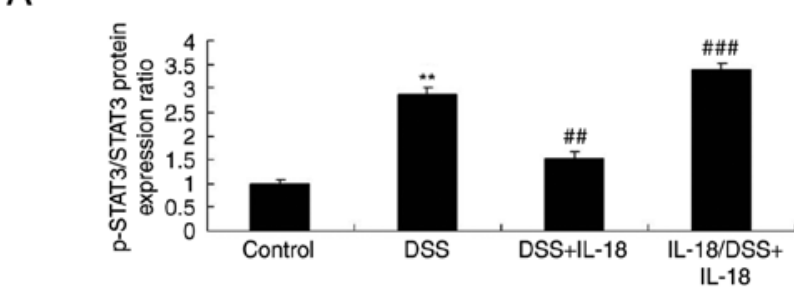

B

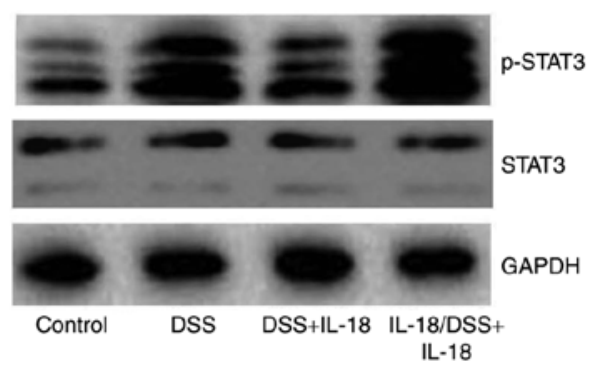

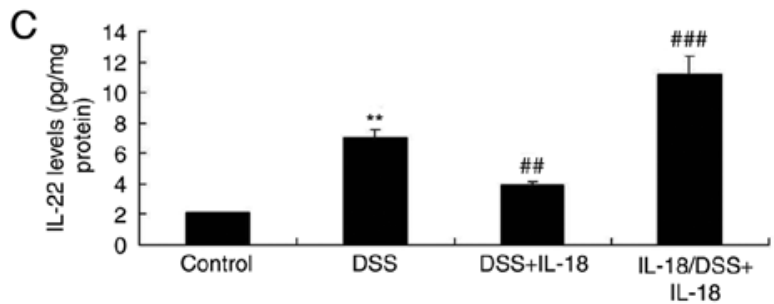

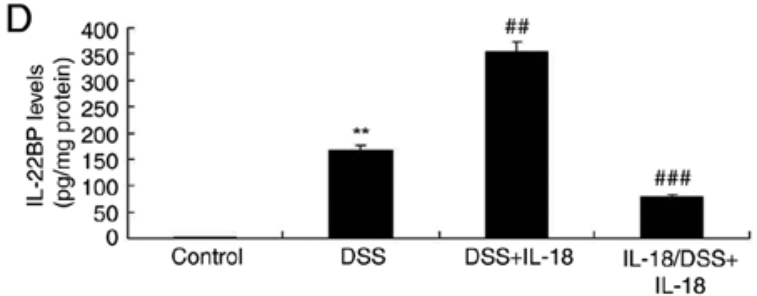

Figure 9. Dual roles of IL-18 in the IL-22/STAT3 signaling pathway in colitis. (A) p-STAT3 and total STAT3 protein expression was quantified by western blot analysis. (B) representative blot images. (C) IL-22 and (D) IL-22BP levels were measured by ELISA in the colon tissues of the experimental mice. ${ }^{* *} \mathrm{P}<0.01$ vs. control group; ${ }^{\# \#} \mathrm{P}<0.01$ and ${ }^{\# \# \#} \mathrm{P}<0.001$ vs. DSS group. IL, interleukin; STAT, signal transducer and activator of transcription; $\mathrm{p}-$-, phosphorylated; IL-22BP, IL-22 binding protein.

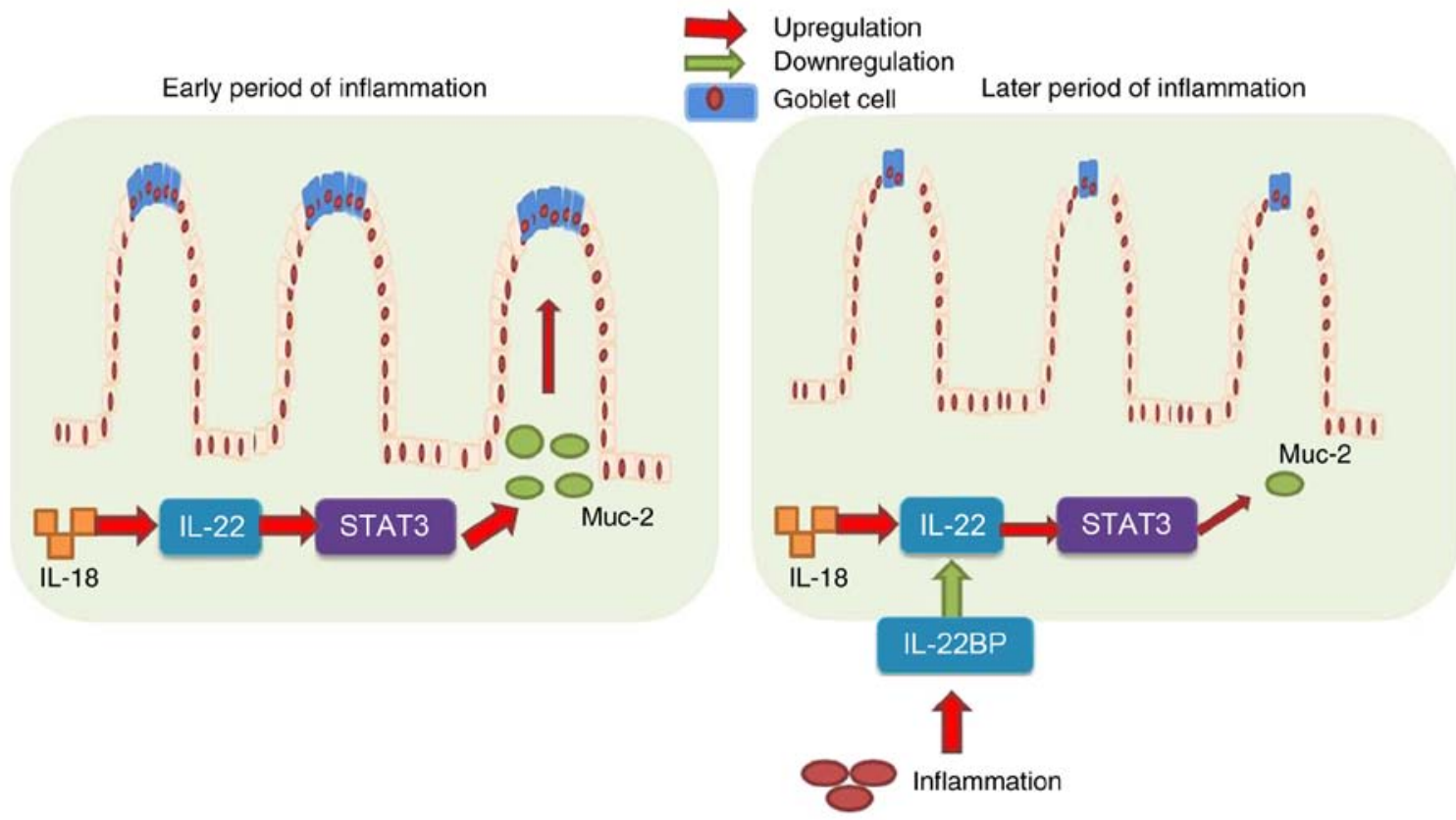

Figure 10. Dual roles of IL-18 in colitis by regulating the function of goblet cells via the IL-22/STAT3 signaling pathway. IL, interleukin; STAT, signal transducer and activator of transcription; IL-22BP, IL-22 binding protein; Muc-2, mucin 2.

IL-22 is involved in epithelial repair (26). The present results demonstrated that pre-treatment with IL-18 increased body weight, augmented colon length and reduced inflammatory infiltration in mice with DSS-induced colitis, while later treatment with IL-18 reduced body weight, decreased colon length and increased inflammatory infiltration in mice with DSS-induced colitis. Therefore, IL-18 possessed a dual function in colitis, with anti-inflammatory effects observed in the early stage of the disease, and pro-inflammatory effects observed in the later stages. The present study focused on the dual roles of IL-18 in colitis, so the exact mechanisms of how IL-18 regulates the function of goblet cells remain unknown. Further studies will assess in the future whether IL-18 alone, in the absence of DSS, may be sufficient to induce inflammation and colitis.

IL-22 is produced by innate lymphoid cells, T-helper (Th) 17 cells and Th22 cells. The membrane-binding IL-22 receptor 1 (IL-22R1) is not present in immune cells, but is expressed in tissues, such as in epithelial cells of gastrointestinal tract and skin (10). IL-22 serves a critical role in promoting anti-microbial immunity via inducing AMPs, and in tissue repair via inducing epithelial cell proliferation and survival (27). However, IL-22 can also promote skin or intestinal pathological inflammatory reactions in mouse models (27). Its concentration is increased in multiple human diseases, including psoriasis, rheumatoid arthritis, infection 
and IBD (28). Based on the multiple effects of IL-22, it is known that such cytokine can transmit signals through STAT3, which is vital to wound healing and tumor development. Yet, the role of IL-22 in tumor development remains controversial, since both suppression and promotion have been reported (28). The present study indicated that pre-treatment with IL-18 induced Stat3 activation, increased IL-22 levels and reduced IL-22BP levels in DSS-induced colitis. Treatment with IL-18 at later stages suppressed Stat 3 activation, decreased IL-22 levels and induced IL-22BP levels in DSS-induced colitis. These results suggest that the anti-inflammatory effect of IL-18 in the early stage of colitis-associated inflammation activated the IL-22/STAT3 signaling pathway, while the pro-inflammatory effects of IL-18 at the later stages of the disease suppressed the IL-22/STAT3 signaling pathway, by activating IL-22 BP. A previous study has demonstrated that AIM2 inflammasome is a central regulator of intestinal homeostasis through the IL-18/IL-22/STAT3 pathway (29).

UC occurs in the mucin layer and is characterized by goblet cell consumption. It is manifested with strong expression of Muc-2 and Muc-4, but low expression of Muc-1 and Muc-3 (30). Therefore, insufficient IL-22 production may promote the consumption of goblet cells and damage the formation of mucus layer in UC (30). Goblet cells specifically produce Muc, but can also produce other molecules involved in colitis regulation and deterioration. Notably, IL-22 downregulates the expression of goblet cell-derived RELM $\beta$ (a potential pathogenic goblet cell product) (31). The present findings indicated that pre-treatment with IL-18 promoted Muc-2 expression, increased the function and quantity of goblet cells and increased RELM $\beta$ and TFF3 mRNA levels in colon tissues from mice with DSS-induced colitis. Treatment with IL-18 at later stages reduced Muc-2 expression, decreased the function and quantity of goblet cells and increased RELM $\beta$ and TFF3 mRNA levels in DSS-induced colitis. The anti-inflammatory effect of IL-18 in early inflammation promoted the function and quantity of goblet cell, while the pro-inflammatory effects of IL-18 inhibited the function and quantity of goblet cells in later stages. Sugimoto et al (31) reported that IL-18 inhibited goblet cell maturation by regulating the transcriptional program instructing goblet cell development.

The present study analyzed IL-18 (rs187238, -137G/C) in patients with colon cancer, $\mathrm{CD}$ or UC, through a meta-analysis of published cohorts. Then, in vivo experiments demonstrated a dual function for IL-18 in a mouse model of colitis, through regulating the function of goblet cells. However, the present study did not analyze the role of IL-18 on cancer cells or tissues, and therefore, the effects of IL-18 on colon cancer remain unknown and will require further research.

In conclusion, the results of the present study demonstrated that IL-18 prevented DSS-induced colitis through recovering goblet cells in the early stages of colitis-associated inflammation, via IL-22/STAT3 signaling (Fig. 10). However, IL-18 at the later stages of the disease induced DSS-induced inflammation, increased IL-22BP expression, and suppressed IL-22/STAT3 signaling to reduce goblet cells and promote the development and progression of colitis (Fig. 10). These results provided evidence that IL-18 may serve as a useful drug candidate for colitis therapy, which warrants further research in the application of IL-18 in colitis treatment.

\section{Acknowledgements}

Not applicable.

\section{Funding}

The present study was financially supported by the National Natural Science Foundation of China (grants nos. 81430091, 81720108032, 91429308, 81603193 and $81421005)$, the project for Major New Drugs Innovation and Development (grant no. 2015ZX09501010), the 111 Project (grant no. G20582017001), State Key Laboratory of Natural Medicines at China Pharmaceutical University (grant no. SKLNMZZCX201610), and the Fundamental Research Funds for the Central Universities (grant no. 2016ZPY011).

\section{Availability of data and materials}

The datasets used and/or analyzed during the present study are available from the corresponding author on reasonable request.

\section{Authors' contributions}

LC and $\mathrm{HH}$ conceived and designed the experiments. ZP performed the experiments. ZP, YC, WZ, HS, HX and TM analyzed the data. ZP wrote the manuscript. All authors read and approved the manuscript and agree to be accountable for all aspects of the research in ensuring that the accuracy or integrity of any part of the work are appropriately investigated and resolved.

\section{Ethics approval and consent to participate}

Protocols involving animals were approved by the Institutional Animal Care and Welfare Committee of China Pharmaceutical University.

\section{Patient consent for publication}

Not applicable.

\section{Competing interests}

The authors declare that they have no competing interests.

\section{References}

1. D'Haens G, Vermeire S, Lambrecht G, Baert F, Bossuyt P, Pariente B, Buisson A, Bouhnik Y, Filippi J, Vander Woude J, et al: Increasing infliximab dose based on symptoms, biomarkers, and serum drug concentrations does not increase clinical, endoscopic, and corticosteroid-free remission in patients with active luminal Crohn's disease. Gastroenterology 154: 1343-1351.e1, 2018.

2. Tan B, Li P, Lv H, Yang H, Li Y, Li J, Wang O and Qian JM: Treatment of vitamin D deficiency in Chinese inflammatory bowel disease patients: A prospective, randomized, open-label, pilot study. J Dig Dis 19: 215-224, 2018.

3. Ling XH, Yu X, Kong DJ, Hu CY, Hong Y and Yang XM: Treatment of inflammatory bowel disease with Chinese drugs administered by both oral intake and retention enema. Chin J Integr Med 16: 222-228, 2010.

4. Buckley JP, Kappelman MD, Allen JK, Van Meter SA and Cook SF: The burden of comedication among patients with inflammatory bowel disease. Inflamm Bowel Dis 19: 2725-2736, 2013. 
5. Sun CM, Wu J,Zhang H, Shi G and ChenZT: Circulating miR-125a butnotmiR-125bisdecreasedinactivedisease statusandnegatively correlates with disease severity as well as inflammatory cytokines in patients with Crohn's disease. World J Gastroenterol 23: 7888-7898, 2017

6. Maerten P, Shen C, Colpaert S, Liu Z, Bullens DA, van Assche G, Penninckx F, Geboes K, Vanham G, Rutgeerts P, et al: Involvement of interleukin 18 in Crohn's disease: Evidence from in vitro analysis of human gut inflammatory cells and from experimental colitis models. Clin Exp Immunol 135: 310-317, 2004.

7. Reuter BK and Pizarro TT: Commentary: The role of the IL-18 system and other members of the IL-1R/TLR superfamily in innate mucosal immunity and the pathogenesis of inflammatory bowel disease: Friend or foe? Eur J Immunol 34: 2347-2355, 2004.

8. Fang L, Pang Z, Shu W, Wu W, Sun M, Cong Y and Liu Z: Anti-TNF Therapy induces CD4 ${ }^{+}$T-cell production of IL-22 and promotes epithelial repairs in patients with Crohn's disease. Inflamm Bowel Dis 24: 1733-1744, 2018.

9. Yang GX, Sun Y, Tsuneyama K, Zhang W, Leung PS, He XS Ansari AA, Bowlus C, Ridgway WM and Gershwin ME: Endogenous interleukin-22 protects against inflammatory bowel disease but not autoimmune cholangitis in dominant negative form of transforming growth factor beta receptor type II mice. Clin Exp Immunol 185: 154-164, 2016.

10. Li LJ, Gong C, Zhao MH and Feng BS: Role of interleukin-22 in inflammatory bowel disease. World J Gastroentero 20 18177-18188, 2014

11. Mizoguchi A: Healing of intestinal inflammation by IL-22. Inflamm Bowel Dis 18: 1777-1784, 2012.

12. Arj A, Razavizadeh M, Mohammadi H, Nikoueinejad $\mathrm{H}$ and Akbari H: The correlation between the numerical status of Th22 cells and serum level of IL-22 with severity of ulcerative colitis. Iran J Allergy Asthma Immuno 17: 78-84, 2018.

13. Livak KJ and Schmittgen TD: Analysis of relative gene expression data using real-time quantitative PCR and the $2^{-\Delta \Delta C_{\mathrm{T}}}$ method. Methods 25: 402-408, 2001.

14. Nikiteas N, Yannopoulos A, Chatzitheofylaktou A and Tsigris C: Heterozygosity for interleukin-18-607 A/C polymorphism is associated with risk for colorectal cancer. Anticancer Res 27: 3849-3853, 2007.

15. Haghshenas MR, Hosseini SV, Mahmoudi M, Saberi-Firozi M, Farjadian S and Ghaderi A: IL-18 serum level and IL-18 promoter gene polymorphism in Iranian patients with gastrointestinal cancers. J Gastroenterol Hepatol 24: 1119-1122, 2009.

16. Guo JY, Qin AQ, Li RK, Yang CM, Huang FD, Huang ZY and Guo HJ: Association of the IL-18 gene polymorphism with susceptibility to colorectal cancer. Zhonghua Wei Chang Wai Ke Za Zhi 15: 400-403, 2012 (In Chinese).

17. Ben Aleya W, Sfar I, Habibi I, Mouelhi L, Aouadi H, Makhlouf M, Ayed-Jendoubi S, Najjar T, Ben Abdallah T, Ayed K, et al: Interleukin-18 gene polymorphisms in tunisian patients with inflammatory bowel disease. Digestion 83: 269-274, 2011.

18. Takagawa T, Tamura K, Takeda N, Tomita T, Ohda Y, Fukunaga K, Hida N, Ohnishi K, Hori K, Kosaka T, et al: Association between IL-18 gene promoter polymorphisms and inflammatory bowel disease in a Japanese population. Inflamm Bowel Dis 11: 1038-1043, 2005.

19. Aizawa Y, Sutoh S, Matsuoka M, Negishi M, Torii A, Miyakawa Y, Sugisaka H, Nakamura M and Toda G: Association of interleukin-18 gene single-nucleotide polymorphisms with susceptibility to inflammatory bowel disease. Tissue Antigens 65 : $88-92,2005$
20. Haas SL, Andreas Koch W, Schreiber S, Reinhard I, Koyama N, Singer MV and Böcker U: -137 (G/C) IL-18 promoter polymorphism in patients with inflammatory bowel disease. Scand J Gastroentero 40: 1438-1443, 2005.

21. Dong YB and Chen GY: Association analysis of IL-18 gene polymorphisms and ulcerative colitis in Chinese Han population. Chin J Clin Gastroenterol 21: 21-22, 2009 (In Chinese).

22. Bank S, Andersen PS, Burisch J, Pedersen N, Roug S, Galsgaard J, Ydegaard Turino S, Brodersen JB, Rashid S, Kaiser Rasmussen B, et al: Polymorphisms in the toll-like receptor and the IL-23/IL-17 pathways were associated with susceptibility to inflammatory bowel disease in a danish cohort. PLoS One 10: e0145302, 2015.

23. Dong YB, Bo WL, Feng XB and Chen GY: Association between single nucleotide polymorphismin of interleukin-18 gene and ulcerative colitis in Han population of Shanghai. World Chin J Digestology 16: 2785-2787, 2008 (In Chinese).

24. Motamed F, Famouri F, Najafi M, Moazzami K, Farahmand F, Khodadad A, Fallahi GH, Khatami GR and Rezaei N: Response to induction therapy in a pediatric population of inflammatory bowel disease. Z Gastroenterol 48: 748-752, 2010.

25. Wiercinska-Drapalo A, Flisiak R, Jaroszewicz J and Prokopowicz D: Plasma interleukin-18 reflects severity of ulcerative colitis. World J Gastroenterol 11: 605-608, 2005.

26. Striz I: Cytokines of the IL-1 family: Recognized targets in chronic inflammation underrated in organ transplantations. Clin Sci 131: 2241-2256, 2017.

27. Tillack C, Ehmann LM, Friedrich M, Laubender RP, Papay P, Vogelsang H, Stallhofer J, Beigel F, Bedynek A, Wetzke M, et al: Anti-TNF antibody-induced psoriasiform skin lesions in patients with inflammatory bowel disease are characterised by interferon-gamma-expressing Th1 cells and IL-17A/IL-22expressing Th17 cells and respond to anti-IL-12/IL-23 antibody treatment. Gut 63: 567-577, 2014.

28. Yu LZ, Wang HY, Yang SP, Yuan ZP, Xu FY, Sun C and Shi RH: Expression of interleukin-22/STAT3 signaling pathway in ulcerative colitis and related carcinogenesis. World J Gastroenterol. 19: 2638-2649, 2013

29. Ratsimandresy RA, Indramohan M, Dorfleutner A and Stehlik C: The AIM2 inflammasome is a central regulator of intestinal homeostasis through the IL-18/IL-22/STAT3 pathway. Cell Mol Immunol 14: 127-142, 2017.

30. Turner JE, Stockinger B and Helmby H: IL-22 mediates goblet cell hyperplasia and worm expulsion in intestinal helminth infection. PLoS Pathog 9: e1003698, 2013.

31. Sugimoto K, Ogawa A, Mizoguchi E, Shimomura Y, Andoh A, Bhan AK, Blumberg RS, Xavier RJ and Mizoguchi A: IL-22 ameliorates intestinal inflammation in a mouse model of ulcerative colitis. J Clin Invest 118: 534-544, 2008.

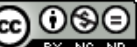

This work is licensed under a Creative Commons Attribution-NonCommercial-NoDerivatives 4.0 International (CC BY-NC-ND 4.0) License. 